\title{
Design and Material Optimisation of a Solar Dryer - Tray Section
}

\author{
H. Bishwash ${ }^{1 *}$, S. Bobadi ${ }^{2}$, M.Nikam ${ }^{3}$ \\ ${ }^{1,2}$ UG Student, Bharati Vidyapeeth College of Engineering, Kharghar, Navi Mumbai, India \\ ${ }^{3}$ Asst. Professor, Bharati Vidyapeeth College of Engineering, Kharghar, Navi Mumbai, India \\ \{himanshub1285@gmail.com\}
}

\begin{abstract}
India is a great country with about 160 million hectares of arable land. It is the second highest producer of agro-products in the world. $40 \%$ of its GDP is agriculture based. However, in the recent times, the contribution of agriculture to the GDP and area of arable land has reduced considerably mainly due to the loss of agriculture product due to improper storage and also less income from the product due to its seasonal nature. Solar dryer removes moisture from the food products, thus making it available through the year, maintaining its quality and thus ensuring proper income from the product. This paper deals with ways to improve the thermal efficiency of a solar dryer by studying the various materials that can be used to manufacture the tray of the dryer and also suggesting a design shape for the dryer tray so that more heating is achieved from the same.
\end{abstract}

Keywords: Solar Dryer, Tray, Fins, Corrugated, Dehydrated

\section{Introduction}

The number of agro-products produced by India is quite abundant. It covers a wide variety of products, most of them, however having a perishable nature. 85 million tonnes of vegetables and around 50 million tonnes of fruits are produced every year. However, the store facility in the country is not quite up to the mark. The number of cold storage units in the country is quite less relative the requirement and so most of the food product that is produced is wasted due to improper storage. This makes it imperative for a farmer to the sell the product in wholesale. This reduces the per capita income of the farmer as the products sold in wholesale are sold at lower cost and then for the rest of the year he doesn't really has a source of income. This non-uniformity in income has put a big economic strain on the farmers and due to this the number of farmers committing suicide every year is increasing constantly. Solar dryer is a revolutionary product that can elevate the economic stress on the farmers. This product allows the farmers to dry the food products so that they do not degrade or degrade at a very low rate. Thus, a seasonal product that is produced at a given time of the year can be sold by the farmer after drying at any time of the year at a cost that is higher than cost of the original fresh product. This also creates a source of income for the local women as they can be educated to operate and maintain the product and also how to manufacture it locally.

In the following paper, ways to improve the efficiency of the existing solar dryer is discussed. For this the dryer made by AA Gatea [1] is studied and method to improve the efficiency of the same is discussed. For this various alternative material and the various shapes for the dryer trays were considered and simulations were carried out to support the results.

\section{Literature Survey}

The initial study included reading various papers and literature available over the internet and other sources. The papers explained the various technologies and scope of the solar drying technique[2][3]-[6]. One of the papers explained the design of the most common form of solar dryer, 'The Solar Convection Dryer' [1], [5], [7], [8].

B. Iyer, S. Nalbalwar and R. Pawade (Eds.)

ICCASP/ICMMD-2016. Advances in Intelligent Systems Research.

Vol. 137, Pp. 27-34.

(C) 2017. The authors - Published by Atlantis Press

This is an open access article under the CC BY-NC license (http://creativecommons.org/licens)es/by-nc/4.0/). 
We learnt about the basic design of the dryer, its design features, the various factors to be considered while designing and much more. The above literature helped us in understanding the principles of the dryer. With further research, we could narrow down our domain of interest to optimisation of heating tray of the dryer. We understood the basic construction and design of the tray[1], [6], [9]. After studying we realised that among the factors responsible for the reduced efficiency of dryers, a big factor is the loss of heat energy at various places in the tray. As these losses are unavoidable, we decided to find out a way to increase the transfer of heat from the tray to the flowing air[10]. For this we considered many options after studying the various ways to improve heat transfer and the details of the same form the papers available. A study of various methods to improve the heat transfer from a surface to the flowing air helped us in selecting the method that will be feasible and its practicality. After considering the various aspects, the models were designed and the trials were made. All the literature regarding the calculations was obtained from the various books related to heat and mass transfer.

(Rajput, 2010) (Rathore, 2015)

\section{Design of the Dryer}

The basic design of the solar convection dryer is shown below[1]:

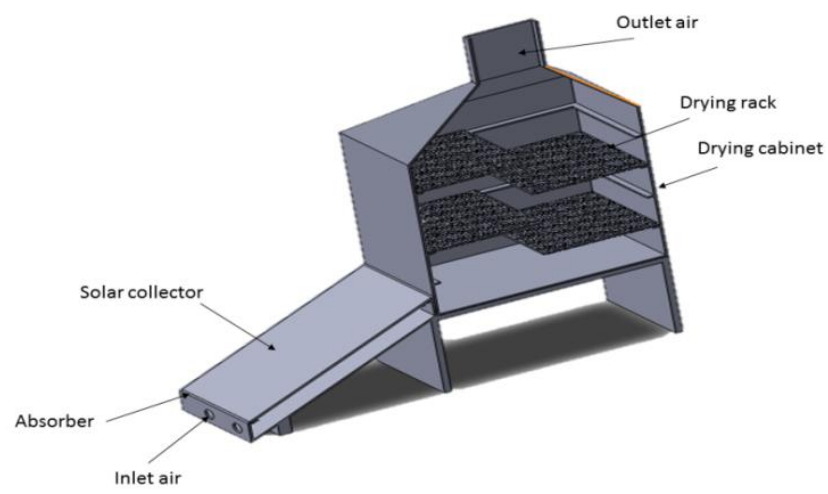

Fig. 1. Section View of the dryer

\section{Design Details}

The design is based on the model used by AA Gatea [1] for his analysis. The model was made using local materials. So, dimensions can be chosen as per the availability of materials. For model testing and prototyping based analysis, we chose a similar model with equivalent features but different dimensions. The inclination of the tray is obtained from the formula given in the paper and adjusted for the conditions in India. The design of the chimney and the dryer tray chamber is the standard one suggested in the various papers and the thus the dimensions for our model are accordingly chosen. Use of same model allows comparison. Fig 2. shows the dimensions of the design chosen. 


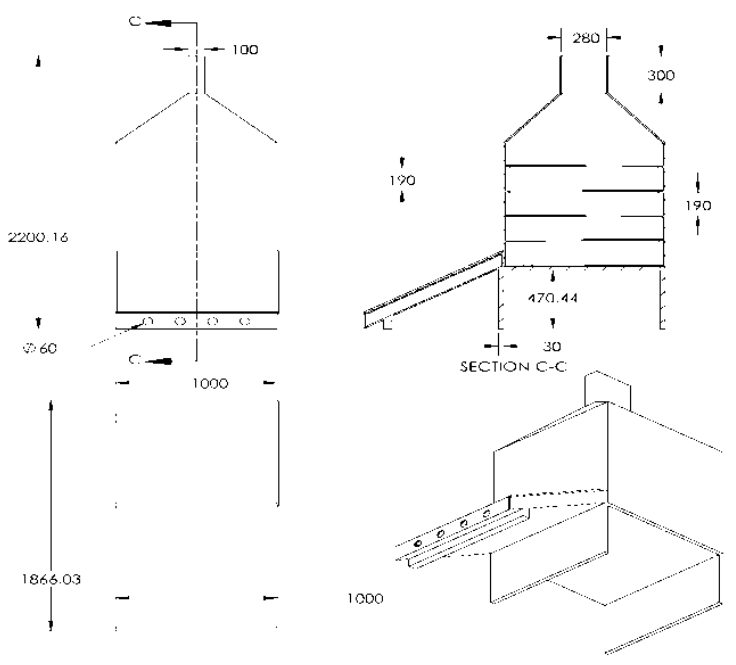

Fig. 2. Dimensional Details of the Dryer (Solidworks)

\section{Problem Definition}

To study the heat transfer and the transient conditions (temperature, heat flow etc.) of air flowing over the dryer tray having various designs and various materials.

\section{Analysis of the tray}

Theanalysis of the tray is based on the basic phenomenon of convective heat transfer from a heated plate to a fluid that flows above the tray. (Rathore, 2015)

For a flat plate/ corrugated plates: [12]

$\mathrm{q}_{\mathrm{conv}}=\mathrm{h}\left(\mathrm{T}_{\mathrm{s}}-\mathrm{T}_{\text {inf }}\right)$ (Rathore, 2015) (Standard Notations followed by the book)

a) For a flat plate with cylindrical fins (Uniform $\mathrm{C} / \mathrm{S}$ ):

For the fin being infinitely long (Rajput, 2010): [11]

Theta $=\mathrm{C}_{1} \mathrm{e}^{\mathrm{mx}}+\mathrm{C}_{2} \mathrm{e}_{-}{ }^{\mathrm{mx}}, \mathrm{m}=\operatorname{sqrt}\left(\mathrm{hP} / \mathrm{kA}_{\mathrm{cs}}\right), \mathrm{Q}_{\text {fin }}=\operatorname{sqrt}\left(\mathrm{PhkA}_{\mathrm{cs}}\right) *\left(\mathrm{t}_{\mathrm{o}}-\mathrm{ti}_{\mathrm{nf}}\right)(2)$

b) For a flat plate with cylindrical fins (Taper C/S): [11]

c) Formulas may be obtained from the referred book (Rajput, 2010)(3)

\section{Assumptions}

1. The solar radiation falling on tray is $234 \mathrm{~W} / \mathrm{m} 2 \mathrm{~K}$. (17\% of $1380 \mathrm{~W} / \mathrm{m} 2 \mathrm{~K})$. [13]

2. The tray is kept open, no glazing and two sides and base are perfectly insulated.

3. Properties of air: (Naturally Convected)

4. Density: $1.225 \mathrm{~kg} / \mathrm{m} 3$

5. Thermal Conductivity: $0.0242 \mathrm{~W} / \mathrm{mK}$

6. Convection Coefficient: $5 \mathrm{~W} / \mathrm{m} 2 \mathrm{~K}$

7. The material is homogenous and isotropic.

8. Paint used is a carbon black paint with matte finish with emissivity 0.88 and film thickness: $6-10$ mils (Neglect) 


\section{Tray Specifications}

Table 1 Design Details

\begin{tabular}{|c|c|c|c|c|c|}
\hline \multicolumn{2}{|c|}{ Type of tray } & Dimension & Thickness & $\begin{array}{l}\text { Inclination } \\
\text { with } \\
\text { horizontal }\end{array}$ & Others \\
\hline \multicolumn{2}{|l|}{ Flat } & \multirow[t]{5}{*}{$(1 * 1) \mathrm{m}$} & \multirow{5}{*}{$\begin{array}{l}3 \mathrm{~mm} \\
\text { (Gauge 26) }\end{array}$} & \multirow[t]{5}{*}{$30^{\circ}$} & NA \\
\hline \multirow{2}{*}{$\begin{array}{l}\text { With } \\
\text { fins }\end{array}$} & Cylindrical & & & & Fin Height: 40 \\
\hline & $\begin{array}{l}\text { Tapered } \\
\left(13^{\circ}\right)\end{array}$ & & & & $\begin{array}{l}\text { Fin diameter: } 20 \mathrm{~mm} \\
\text { No of fins: } 81\end{array}$ \\
\hline \multicolumn{2}{|c|}{ Corrugated } & & & & $\begin{array}{l}\text { Diameter of semi-circles: } 100 \mathrm{~mm} \\
\text { No of semi-circles: } 10\end{array}$ \\
\hline \multicolumn{2}{|c|}{ Concave } & & & & $\begin{array}{l}\text { Maximum deviation of curve from axis: } \\
\text { 30mm }\end{array}$ \\
\hline
\end{tabular}

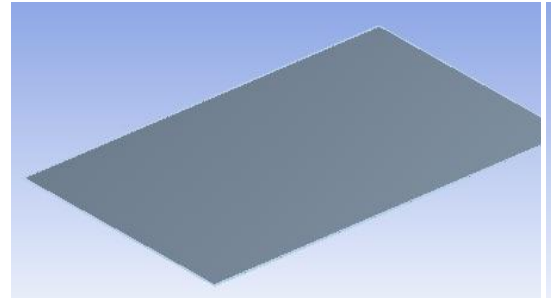

Fig. 3. Flat Plate

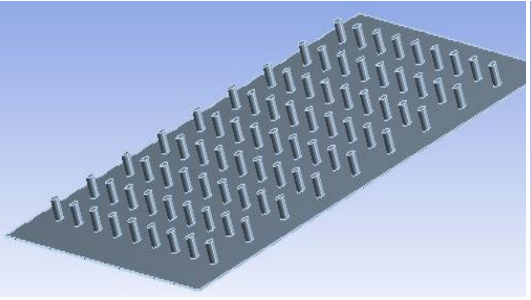

Fig. 4. Circular Fins

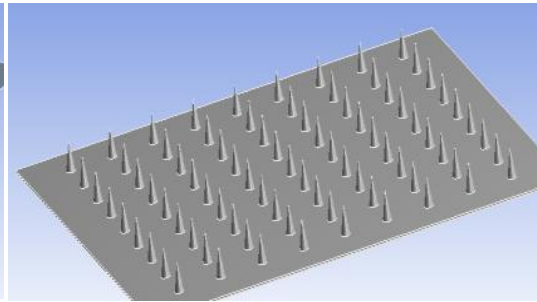

Fig. 5. Tapered Fins

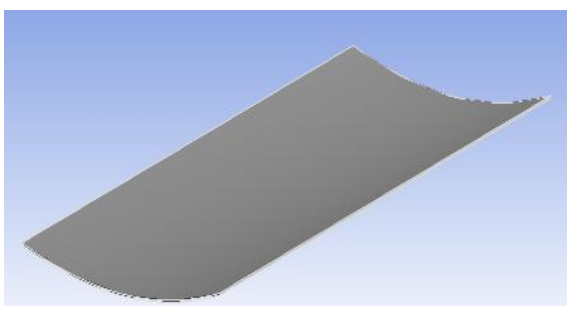

Fig. 6. Concave Plate

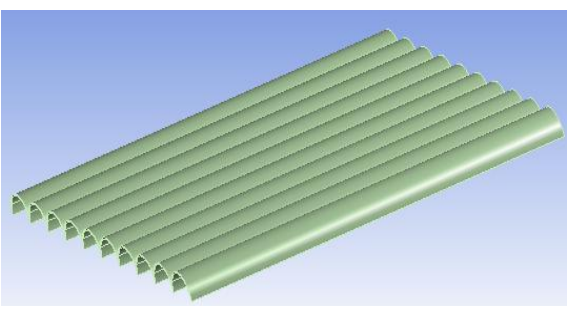

Fig. 7. Corrugated Tray

\section{Model Setup and Results of Simulation}

All the simulations were carried out on Ansys Workbench 14.5 by using the transient thermal analysis and the models were made on the Dassault Solidworks Software. The values are calculated for an exposure of tray to the heat flux for 10 mins

Fig. 8 and Fig. 9 show the load setup and the temperature distribution on the dryer respectively. The load setup is common for all the simulations. The temperature distribution results are also similar in all the simulations.

The temperature distributionappears as shown because as the value of thermal resistance is

$$
\mathrm{Rth}=(\mathrm{L} / \mathrm{kA})
$$

And thus, the value of temperature decreases with the depth of plate.

Also, as for convection, 
$(\mathrm{T}-\mathrm{Tamb}) /($ Tini-Tamb) $=\exp (\mathrm{hAT} / \mathrm{pVc})($ Rajput, 2010- Pg. 292)(5)

Air will heat up with time upto the outlet before achieving a steady state.

As it is quite evident from the above results that the tray outlet temperatures show no significant difference for various materials, no further simulations are run for the given materials and simulations are run only for Aluminium as the base metal for the tray.The material optimisation will thus be based on the material properties, availability and cost.

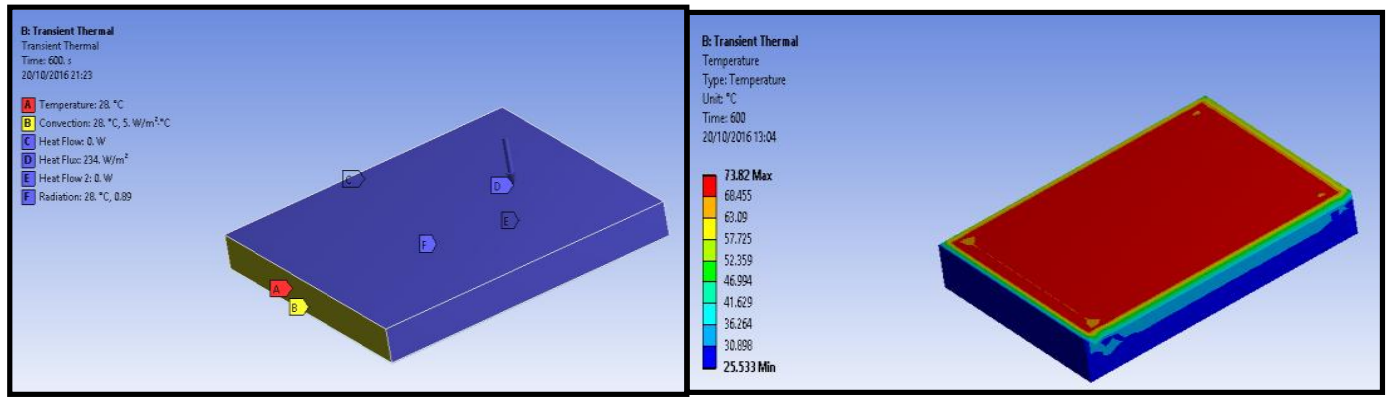

Fig. 8. Load Setup of the Tray

Fig. 9.Temperature Distribution

Table 2 Calculated results for different materials of flat tray

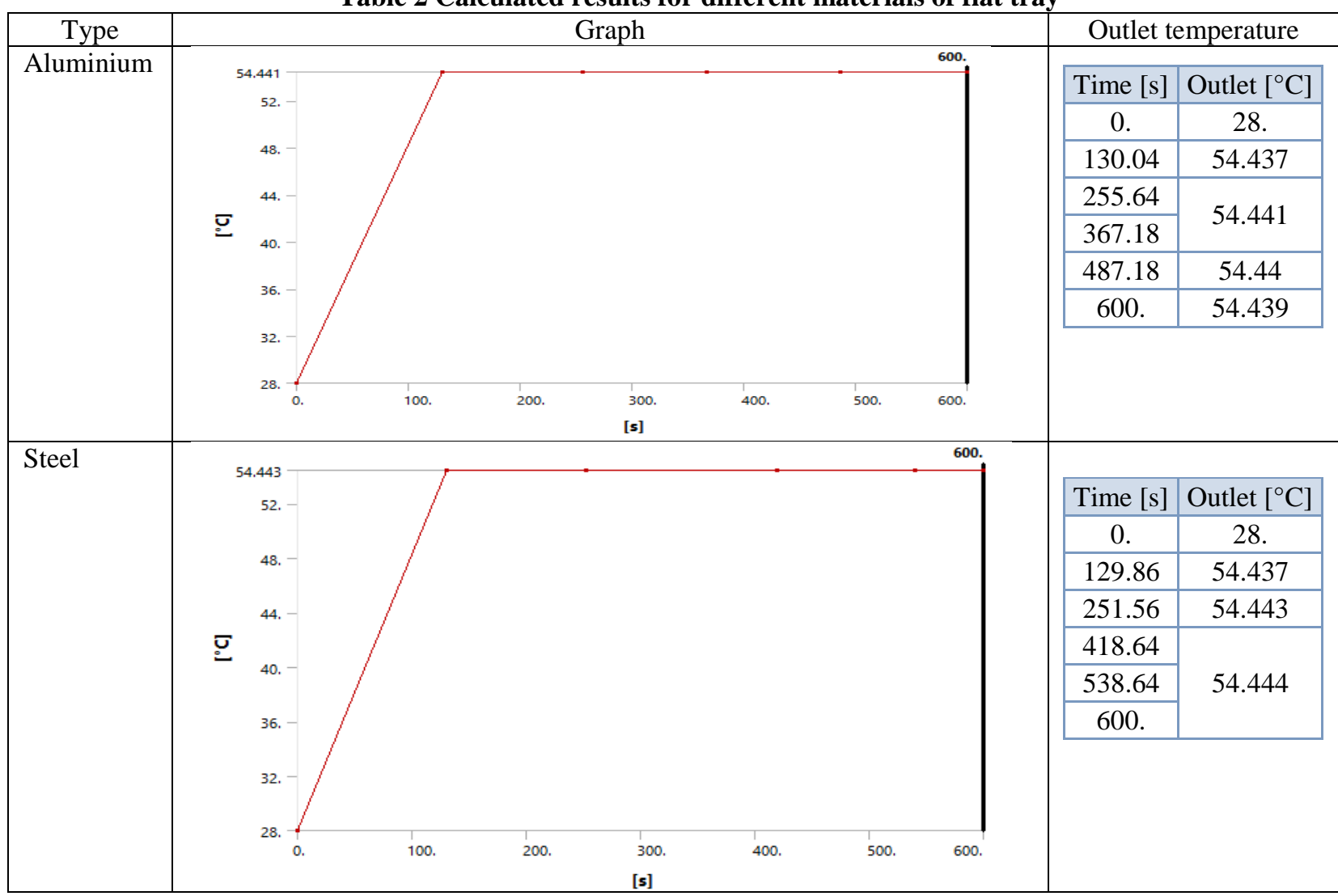




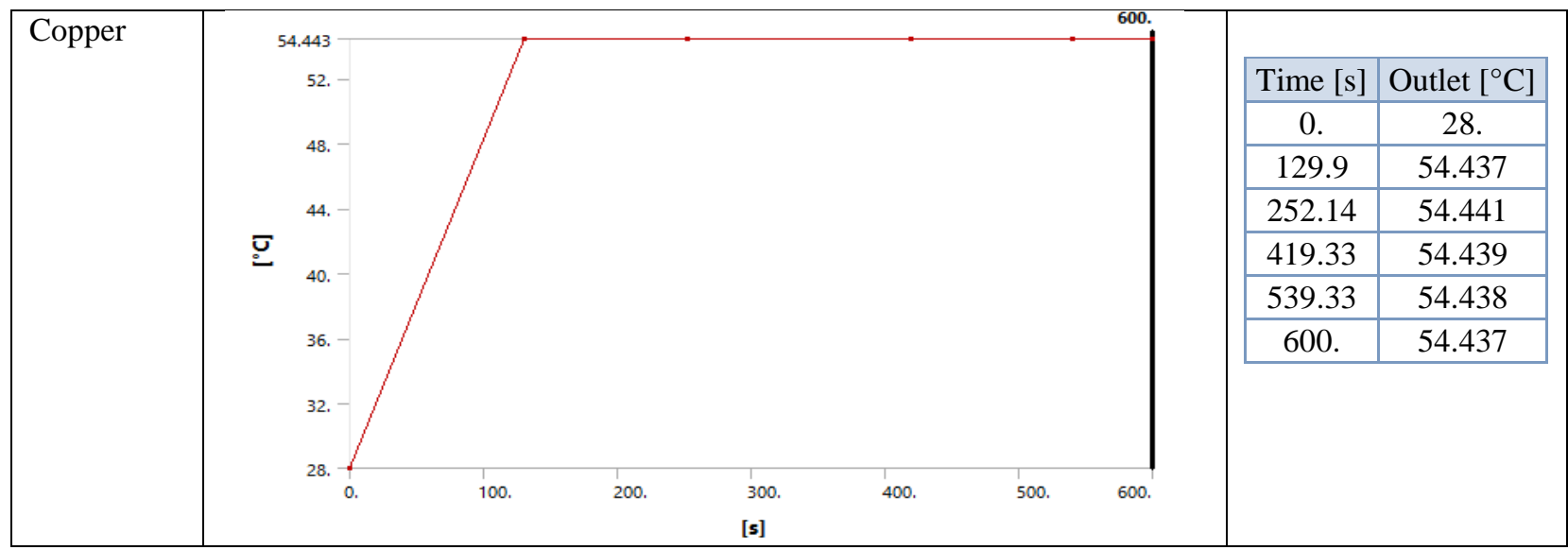

Table 3 Calculated results of different tray types

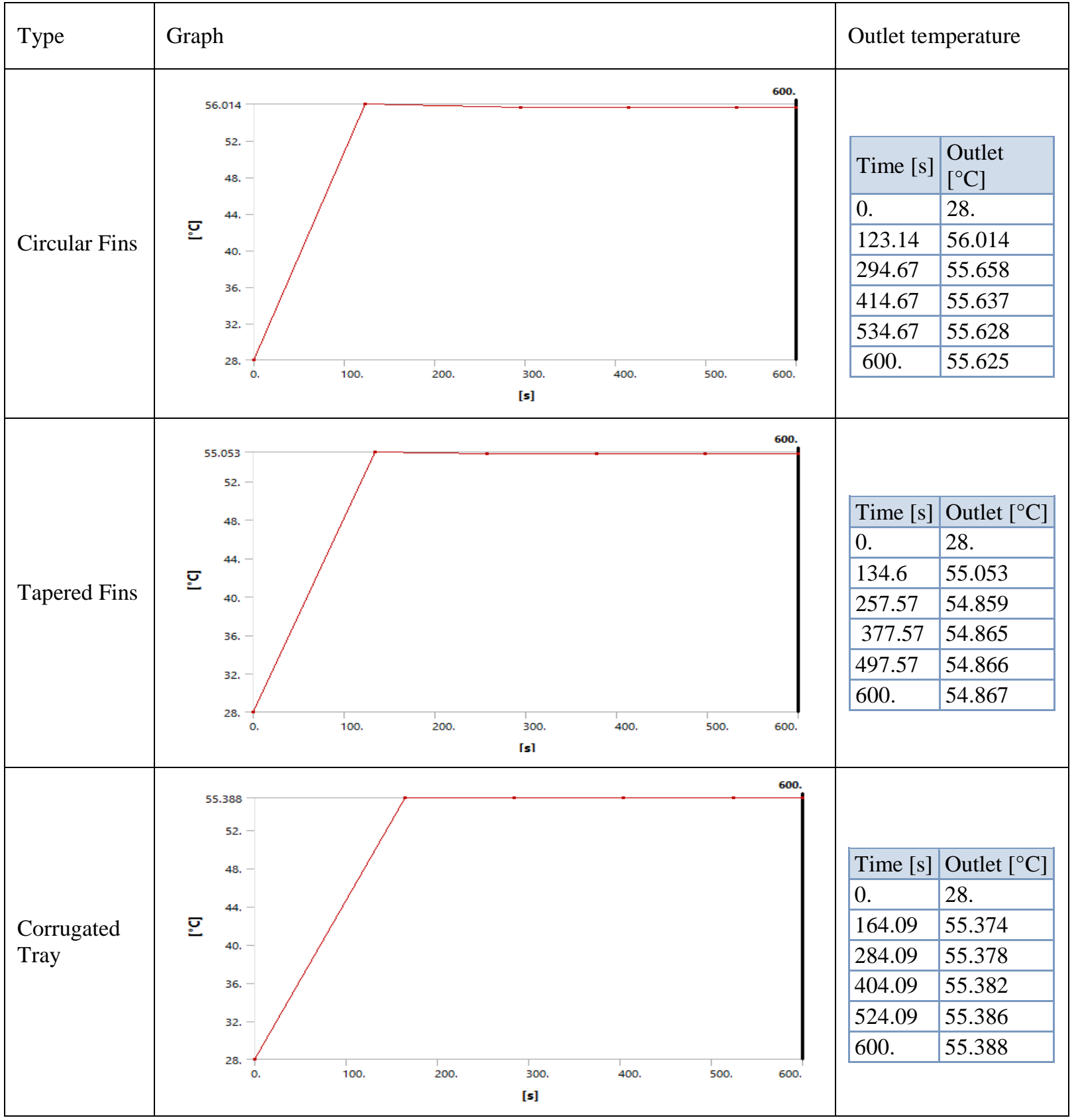




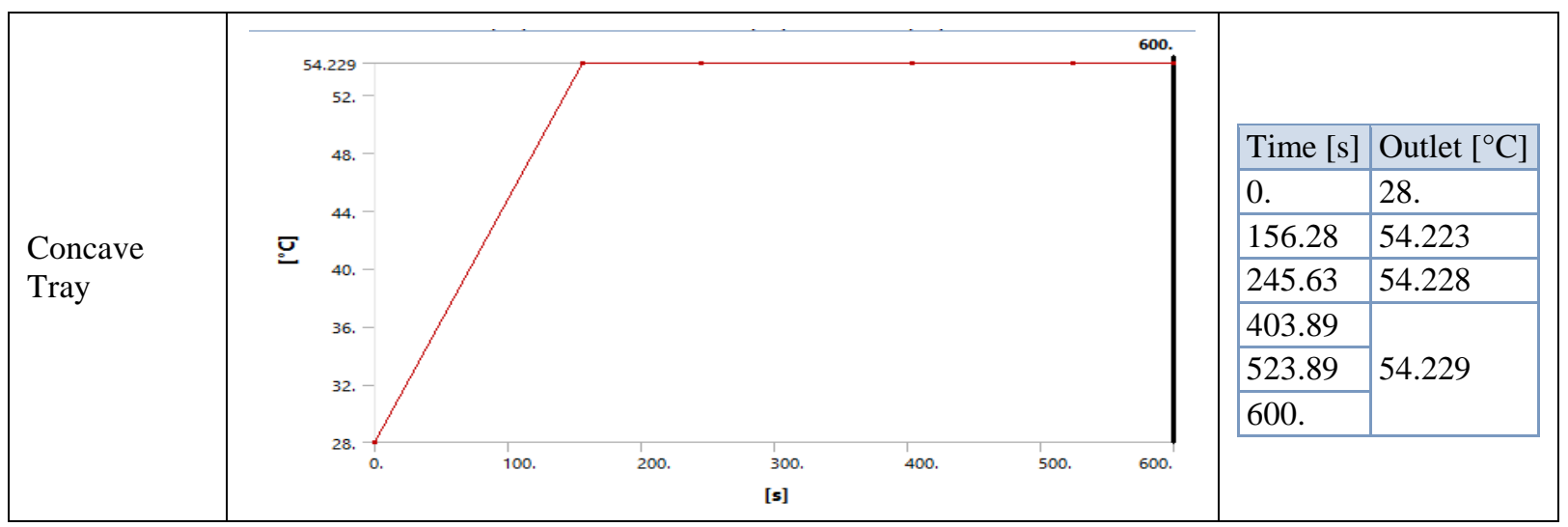

\section{Results and Conclusions}

\section{a. Material Optimisation:}

Here, the use of different materials for the tray does not seem to make a significant difference in the values of outlet temperature. The reason for this may be the low thickness of the plate due to which so significant difference in heat conduction occurs for a perfectly insulated plate. The materials chosen for our study were Aluminium, Copper and Steel.

Copper here has the best thermal conductivity and should be the best suited material for our purpose. However, Copper has low specific heat which means its heat retention will be low. Also, it is heavy and has a high cost. So, we don't choose copper. Steel has low specific heat, high weigh and is costly. So, steel is not chosen. Aluminium has a very low weight. It is quite non-corrosive. Its specific heat is also high and has a good thermal conductivity. Also, it is available at a low cost. So, we choose aluminium as the base material for the tray. This means that the tray is already optimised.

\section{a) Design Optimisation:}

The following values of outlet temperature of air were obtained for the various trays after simulation.

Table 4 Outlet temperature of plates after 10 minutes

\begin{tabular}{|c|c|}
\hline Cylindrical Fins & 55.625 \\
\hline Corrugated Sheets & 55.388 \\
\hline Taper Fins & 54.867 \\
\hline Flat & 54.435 \\
\hline Concave & 54.299 \\
\hline
\end{tabular}

Here the maximum outlet temperature is obtained for the tray with cylindrical fins. Corrugated sheets give a slightly less temperature. However, by manufacturing point of view, corrugated sheets are easily available and can be easily manufactured at a low cost as compared to making fins. Thus, for the given case, temperatures obtained for corrugated sheets are $2.178 \%$ higher than flat plates. So, we choose corrugated sheets over the fins and flat plate.

Thus, heating achieved by corrugated sheets will be comparatively higher and thus it will proportionally reduce the drying time reducing the cost/day of the drying process.

Thus,

a) Proposed Material for tray: Aluminium

b) Proposed Design for tray: Corrugated Sheets 


\section{Acknowledgements:}

We are grateful to Mr. Manoj Nikam (Assistant Professor, BVCOE) for guiding us through the entire project. We also like to thank Mr. Ganesh Katke (Assistant Professor, BVCOE) for helping us to use the various design related software. We would like to thank our HOD, Mrs. Sandhya Jadhav and our Principle Dr. MZ Shaikh for their cooperation. We are grateful to the college for providing us the necessary infrastructure.

\section{References}

[1]. A. A. Gatea, "Performance evaluation of a mixed-mode solar dryer for evaporating moisture in beans," J. Agric. Biotechnol. Sustain. Dev., vol. 3, no. 4, pp. 65-71, 2011.

[2]. A. D. Chaudhari and S. P. Salve, "A Review of Solar Dryer Technologies," Int. J. Res. Advent Technol., vol. 2, no. 2, pp. 2321-9637, 2014.

[3]. A. A. El-Sebaii and S. M. Shalaby, "Solar drying of agricultural products: A review," Renew. Sustain. Energy Rev., 2012.

[4]. R. J. Fuller, "SOLAR DRYING -A TECHNOLOGY FOR SUSTAINABLE AGRICULTURE AND FOOD PRODUCTION."

[5]. A. G. M. B. Mustayen, S. Mekhilef, and R. Saidur, "Performance study of different solar dryers: A review," Renewable and Sustainable Energy Reviews. 2014.

[6]. R. Vidya, S. Raju, R. M. Reddy, and E. S. Reddy, "Design and Fabrication of Efficient Solar Dryer," J. Eng. Res. Appl. www.ijera.com ISSN, vol. 3, no. 6.

[7]. A. Madhlopa and Ngwalo G, "CONVECTIVE SOLAR DRYER WITH A WOOD WASTE BACKUP HEATER FOR DEHYDRATION OF FOOD."

[8]. P. C. Phadke, P. V Walke, and V. M. Kriplani, "DIRECT TYPE NATURAL CONVECTION SOLAR DRYER: A REVIEW,” Int. J. Adv. Res. Sci. Eng. IJARSE, no. 402, 2015.

[9]. K. B. Koua, P. Gbaha, E. P. M. Koffi, W. F. Fassinou, and S. Toure, "Modelling of thermal behaviour of a direct solar drier possessing a chimney: Application to the drying of cassava," Indian J. Sci. Technol., 2011.

[10]. R. Dylewski and J. Adamczyk, "The comparison of thermal insulation types of plaster with cement plaster," J. Clean. Prod., 2014. 